\title{
KARAKTERISASI SUATU IDEAL DARI SEMIGRUP IMPLIKATIF
}

\author{
ELVA SUSANTI \\ Program Studi Magister Matematika, \\ Fakultas Matematika dan Ilmu Pengetahuan Alam, Universitas Andalas, \\ Kampus UNAND Limau Manis Padang, Indonesia, \\ srikandhi_elva@yahoo.co.id
}

\begin{abstract}
Abstrak. Semigrup Implikatif $S$ merupakan suatu himpunan terurut parsial yang bersifat semigrup, semigrup terurut parsial secara negatif (NPO semigrup) dan NPO semigrup komutatif. Selanjutnya didefinisikan himpunan $S(u, v)=\{z \in S \mid u *(v * z)=1\}$, kemudian dari definisi tersebut dapat ditentukan idealnya apabila memenuhi hukum distributif kiri. Ideal merupakan suatu himpunan bagian dari $S$ yang semigrup implikatif dengan memenuhi sifat-sifat tertentu. Pada makalah ini akan dikaji tentang Ideal dari Semigrup Implikatif, karakteristik dari ideal dan juga diberikan beberapa contoh dari semigrup implikatif yang selanjutnya ditentukan idealnya.
\end{abstract}

Kata Kunci: Semigrup implikatif, NPO semigrup, terurut parsial, komutatif

\section{Pendahuluan}

Semilattice implikatif merupakan suatu sistem aljabar yang mempunyai sistem model logika dengan menggunakan implikasi dan konjungsi tetapi tidak menggunakan proses disjungsi. Pada [4], Nemitz telah mempelajari secara sistematik tentang semilattice implikatif. Nemitz memperlihatkan hasil-hasil tertentu dari logika Brouwerian yang dikaji oleh V. Glivenko yang dapat dibuktikan pada semilattice implikatif. Kemudian, Nemitz menyelidiki hubungan antara homomorfisma pada semilattice implikatif dan kernelnya. Selanjutnya, Chan dan Shum pada [1] mengikuti ide Nemitz dengan memperkenalkan istilah baru yakni negatively partially ordered (NPO) semigrup implikatif (semigrup yang terurut parsial secara negatif) dan kemudian mempelajari homomorfisma antara semigrup- semigrup tersebut. Beberapa hasil dari Nemitz tentang semilattice implikatif telah digeneralisasi untuk kasus semigrup implikatif.

Dalam tulisan ini akan diperkenalkan istilah ideal dari semigrup implikatif yang merupakan himpunan bagian khusus (dengan sifat-sifat tertentu). Kemudian akan dikaji karakteristik dari ideal tersebut. Tulisan ini bertujuan untuk mengkaji karakterisasi himpunan bagian $I \subseteq S$ yang merupakan ideal, dimana $S$ adalah suatu semigrup implikatif.

\section{Himpunan Terurut Parsial, Semigrup dan Semigrup Implikatif}

Definisi 2.1. [2] Jika $(a, b) \in R$ dan $R$ bersifat refleksif, anti simetris dan transitif, maka $R$ disebut relasi terurut parsial. 
Misalkan $G$ suatu himpunan yang tak kosong dan $*$ suatu operasi yang didefinisikan di $G$. Operasi * disebut operasi biner di $G$ jika untuk setiap $a, b \in G$ berlaku $a * b \in G$ ( $G$ bersifat tertutup terhadap operasi $*)$. $G$ disebut membentuk semigrup terhadap operasi $*$ jika untuk setiap $a, b, c \in G$ berlaku $a *(b * c)=(a * b) * c(G$ bersifat asosiatif terhadap operasi biner $*$ ).

Definisi 2.2. [3] Semigrup terurut parsial secara negatif (NPO semigrup) adalah suatu himpunan $S$ dengan terurut parsial " $\preceq$ "dan suatu operasi biner "•" sedemikian sehingga untuk semua $x, y, z \in S$ berlaku:

(1) $(x \bullet y) \bullet z=x \bullet(y \bullet z)$.

(2) Jika $x \preceq y \operatorname{maka} x \bullet z \preceq y \bullet z$ dan $z \bullet x \preceq z \bullet y$.

(3) $x \bullet y \preceq x$ dan $x \bullet y \preceq y$.

Definisi 2.3. [3] Semigrup terurut parsial secara negatif $(S, \preceq, \bullet)$ dikatakan implikatif (NPO semigrup implikatif), jika terdapat operasi biner $*: S \times S \rightarrow S$ sehingga untuk setiap elemen $x, y, z$ di $S$ berlaku:

(4) $z \preceq x * y$ jika dan hanya jika $z \bullet x \preceq y$.

Untuk penyederhanaan istilah, NPO semigrup implikatif disebut sebagai semigrup implikatif saja.

Definisi 2.4. [3] Sebuah semigrup implikatif $(S, \preceq, \bullet, *)$ dikatakan komutatif jika memenuhi:

(5) $x \bullet y=y \bullet x$ untuk semua $x, y \in S$, artinya $(S, \bullet)$ adalah semigrup komutatif.

Contoh 2.5. Misalkan $S=\{1, a, b, c, d, 0\}$ dan didefinisikan operasi terurut parsial di $S$ sebagai berikut.

$\langle i\rangle \quad 0 \preceq b \preceq a \preceq 1$.

$\langle i i\rangle 0 \preceq d \preceq a \preceq 1$.

$\langle i i i\rangle 0 \preceq d \preceq c \preceq 1$.

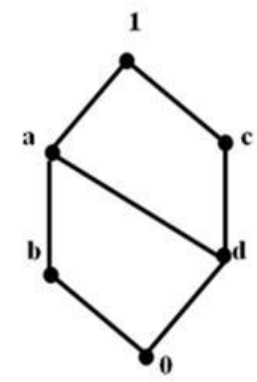

Gambar 1. Diagram Hasse untuk $S=\{1, \mathrm{a}, \mathrm{b}, \mathrm{c}, \mathrm{d}, 0\}$ 
Definisi relasi terurut parsial $\preceq$, dapat juga disajikan diagram Hasse sebagaimana yang diperlihatkan pada Gambar 1 .

Tabel 1 dan 2 berikut adalah definisi dari operasi biner $\bullet$ dan $*$ di $S$ yang merupakan semigrup implikatif.

Tabel 1. Definisi operasi • di $S$

\begin{tabular}{c|cccccc}
\hline$\bullet$ & 1 & $\mathrm{a}$ & $\mathrm{b}$ & $\mathrm{c}$ & $\mathrm{d}$ & 0 \\
\hline 1 & 1 & $\mathrm{a}$ & $\mathrm{b}$ & $\mathrm{c}$ & $\mathrm{d}$ & 0 \\
$\mathrm{a}$ & $\mathrm{a}$ & $\mathrm{b}$ & $\mathrm{b}$ & $\mathrm{d}$ & 0 & 0 \\
$\mathrm{~b}$ & $\mathrm{~b}$ & $\mathrm{~b}$ & $\mathrm{~b}$ & 0 & 0 & 0 \\
$\mathrm{c}$ & $\mathrm{c}$ & $\mathrm{d}$ & 0 & $\mathrm{c}$ & $\mathrm{d}$ & 0 \\
$\mathrm{~d}$ & $\mathrm{~d}$ & 0 & 0 & $\mathrm{~d}$ & 0 & 0 \\
0 & 0 & 0 & 0 & 0 & 0 & 0 \\
\hline
\end{tabular}

Tabel 2. Definisi operasi $*$ di $S$

\begin{tabular}{c|cccccc}
\hline$*$ & 1 & $\mathrm{a}$ & $\mathrm{b}$ & $\mathrm{c}$ & $\mathrm{d}$ & 0 \\
\hline 1 & 1 & $\mathrm{a}$ & $\mathrm{b}$ & $\mathrm{c}$ & $\mathrm{d}$ & 0 \\
$\mathrm{a}$ & 1 & 1 & $\mathrm{a}$ & $\mathrm{c}$ & $\mathrm{c}$ & $\mathrm{d}$ \\
$\mathrm{b}$ & 1 & 1 & 1 & $\mathrm{c}$ & $\mathrm{c}$ & $\mathrm{c}$ \\
$\mathrm{c}$ & 1 & $\mathrm{a}$ & $\mathrm{b}$ & 1 & $\mathrm{a}$ & $\mathrm{b}$ \\
$\mathrm{d}$ & 1 & 1 & $\mathrm{a}$ & 1 & 1 & $\mathrm{a}$ \\
0 & 1 & 1 & 1 & 1 & 1 & 1 \\
\hline
\end{tabular}

Proposisi 2.6. [3] Misalkan $S$ sebuah semigrup implikatif maka untuk setiap $x, y, z \in S$, berlaku:

(6) $x \preceq 1$, dimana $x * x:=1, x=1 * x$,

(7) $x \preceq y *(x \bullet y)$,

(8) $x \preceq x * x^{2}$,

(9) $x \preceq y * x$,

(10) jika $x \preceq y$ maka $x * z \succeq y * z$ dan $z * x \preceq z * y$,

(11) $x \preceq y$ jika dan hanya jika $x * y=1$,

(12) $x *(y * z)=(x \bullet y) * z$,

(13) jika $S$ adalah komutatif maka $x * y \preceq(s \bullet x) *(s \bullet y)$ untuk semua s dalam $S$.

Sekarang perhatikan sifat dasar penting dari sebuah semigrup implikatif komutatif yang mengikuti (5), (6) dan (12).

Proposisi 2.7. [3] Jika $S$ adalah sebuah semigrup implikatif komutatif, maka untuk setiap $x, y, z \in S$, berlaku:

(14) $x *(y * z)=y *(x * z)$,

(15) $y * z \preceq(x * y) *(x * z)$,

(16) $x \preceq(x * y) * y$.

Proposisi 2.8. [5] Untuk semua $x, y \in S$, dimana $S$ merupakan semigrup implikatif komutatif, berlaku:

(a) $y *((y * x) * x)=1$, 
(b) $1 \preceq x \Rightarrow x=1$.

\section{Ideal pada semigrup implikatif}

Misalkan $S$ semigrup implikatif. Dalam bagian ini akan diberikan definisi ideal dari $S$, dan hasil-hasil utama tentang ideal dari $S$.

Definisi 3.1. [3] Sebuah himpunan bagian I dari S disebut ideal jika:

(I1) $x \in S$ dan $a \in I$ berakibat $x * a \in I$,

(I2) $x \in S$ dan $a, b \in I$ berakibat $(a *(b * x)) * x \in I$.

Pada bagian ini akan dibahas mengenai pembuktian lema dan teorema yang berkaitan dengan karakteristik ideal semigrup implikatif.

Lema 3.2. [3] Setiap ideal dari $S$ memuat 1.

Bukti. Misalkan $S$ adalah semigrup implikatif dan $I$ ideal dari $S$. Ambil sebarang ideal, akan ditunjukkan $1 \in I$. Berdasarkan Definisi 3.1(I1), terdapat $x \in S$ dan $a \in I$ maka $x * a \in I$. Misalkan $x=a \in I$ dimana $x * a \in I$ akibatnya $x * x \in I$ artinya $1 \in I$, berdasarkan Proposisi 2.6(6).

Lema 3.3. [3] Jika I adalah ideal dari $S$, maka $(a * x) * x \in I$ untuk semua $a \in I$ dan $x \in S$.

Bukti. Misalkan $S$ adalah semigrup implikatif dan $I$ ideal dari $S$, akan ditunjukkan $(a * x) * x \in I$ untuk semua $a \in I$ dan $x \in S$. Ambil $x \in S, b=1 \in I$ dan $a \in I$. Karena diketahui $I$ ideal, maka berdasarkan Definisi 3.1(I2) berlaku $(a *(b * x)) * x=$ $(a *(1 * x)) * x=(a * x) * x \in I$.

Akibat 3.4. [3] Misalkan I adalah ideal dari S. Jika $a \in I$ dan $a \preceq x$ maka $x \in I$.

Bukti. Misalkan $S$ adalah semigrup implikatif dan $I$ ideal dari $S$, Akan ditunjukkan bahwa jika $a \in I$ dan $a \preceq x$ maka $x \in I$. Ambil $a \preceq x$. Berdasarkan Proposisi 2.6(11), $a \preceq x \Leftrightarrow a * x=1$, dari Proposisi 2.6(6) diperoleh $x=1 * x$. Karena $a * x=1$, maka dari Lema 3.3 diperoleh $x=(a * x) * x \in I$.

Lema 3.5. [3] Misalkan $S$ adalah semigrup implikatif komutatif dan I himpunan bagian dari $S$, sedemikian sehingga

(I3) $1 \in I$,

(I4) untuk semua $x, y, z \in S$ dimana $x *(y * z) \in I$ dan $y \in I$ berakibat $x * z \in I$.

Jika $a \in I$ dan $a \preceq x$, maka $x \in I$.

Bukti. Misalkan $S$ adalah semigrup implikatif komutatif dan $I$ himpunan bagian dari $S$ dengan (I3) dan (I4) dimana $a \in I$ dan $a \preceq x$. Akan ditunjukkan $x \in I$. Jika $a \in I$ dan $x \in S$ maka $a \preceq x$. Karena $a \preceq x$ dan $x \preceq 1$ maka berdasarkan Proposisi 
2.6(11) diperoleh $a * 1=1$ sehingga $x *(a * 1)=x * 1=1 \in I$ dan juga $x=x * 1 \in I$. Dengan demikian terbukti $x \in I$.

Teorema 3.6. [3] Misalkan $S$ adalah semigrup implikatif komutatif. Himpunan bagian I dari $S$ adalah suatu ideal jika dan hanya jika I memenuhi kondisi (I3) dan (I4).

Bukti. $(\Rightarrow)$ Misalkan $S$ adalah semigrup implikatif komutatif dan $I$ ideal dari $S$, akan ditunjukkan $I$ memenuhi kondisi (I3) dan (I4). Karena $I$ ideal dari $S$ maka dari Lema 3.2 diperoleh $1 \in I$. Pilih $x, y, z \in S$ sedemikian rupa sehingga $x *(y * z) \in I$ dan $y \in I$. Perhatikan bahwa:

$$
\begin{aligned}
(x * z) & =1 *(x * z), \quad(\text { Proposisi 2.6(6)) } \\
& =((x *(y * z)) *(x *(y * z))) *(x * z) \text { (Proposisi 2.6(6)) } \\
& =((x *(y * z)) *(y *(x * z))) *(x * z) \in I \text { (Definisi 3.1(I2)). }
\end{aligned}
$$

$(\Leftarrow)$ Akan dibuktikan bahwa Definisi 3.1(I1) dan (I2) berlaku. Misalkan $x \in S$ dan $a \in I$. Karena $x *(a * a)=x * 1=1 \in I$ dari (I3), maka berdasarkan (I4) diperoleh $x * a \in I$, artinya (I1) terpenuhi. Karena $(a * x) *(a * x)=1 \in I$, maka $(a * x) * x \in I$ (Lema 3.5(I4)). Dari Proposisi 2.6(10) dan Proposisi 2.7(15) diperoleh

$$
\begin{aligned}
1 & =((a * x) * x) *((a * x) * x)(\text { Proposisi } 2.6(6)) \\
& \preceq((a * x) * x) *(b *(a * x) *(b * x)) .
\end{aligned}
$$

Akibatnya $1 \preceq((a * x) * x) *(b *(a * x) *(b * x))$. Berdasarkan Proposisi 2.8(b) diperoleh $1=((a * x) * x) *(b *(a * x) *(b * x))$. Kemudian diperoleh $((a * x) * x) \preceq(b *(a * x)) *(b * x)$ untuk semua $b \in I$. Karena $((a * x) * x) \preceq(b *(a * x)) *(b * x)$ dan $((a * x) * x) \in I$ maka dari Akibat 3.4 diperoleh $(b *(a * x)) *(b * x) \in I$. Dengan menggunakan (I4), dapat disimpulkan bahwa $(b *(a * x)) * x \in I$ yang membuktikan (I2). Oleh karena itu $I$ adalah ideal dari $S$.

Selanjutnya akan diberikan definisi suatu himpunan bagian dari $S$ dan akan ditunjukkan bahwa himpunan tersebut merupakan ideal dari $S$.

Definisi 3.7. [3] Untuk suatu $u, v \in S$, didefinisikan suatu himpunan $S(u, v)$ sebagai berikut.

$$
S(u, v)=\{z \in S \mid u *(v * z)=1\} .
$$

Teorema 3.8. [3] Misalkan $S$ memenuhi hukum distributif kiri dibawah operasi *, yaitu $x *(y * z)=(x * y) *(x * z)$ untuk semua $x, y, z \in S$. Untuk setiap $u, v \in S$, himpunan $S(u, v)$ adalah ideal dari $S$.

Bukti. Misalkan $S$ adalah semigrup implikatif yang memenuhi hukum distributif kiri dibawah operasi *. Akan ditunjukkan $S(u, v)$ adalah ideal dari $S$. Ambil $x \in S$ 
dan $a, b \in S(u, v)$ maka

$$
\begin{aligned}
u *(v *(x * a)) & =u *((v * x) *(v * a)) \\
& =(u *(v * x)) *(u *(v * a)) \\
& =(u *(v * x)) * 1 \\
& =1 .
\end{aligned}
$$

Menurut Definisi 3.1, $x \in S$ dan $a \in S(u, v)$. Sehingga $x * a \in S(u, v)$. Selanjutnya,

$$
\begin{aligned}
u *(v *((a *(b * x) * x))) & =u *(v *(a *(b * x))) *(v * x), \\
& =(u *(v *(a *(b * x)))) *(u *(v * x)), \\
& =((u *(v * a)) *(u *(v *(b * x)))) *(u *(v * x)), \\
& =(1 *(u *(v * b)) *(u *(v * x))) *(u *(v * x)), \\
& =(1 *(1 *(u *(v * x)))) *(u *(v * x)), \\
& =(1 *(u *(v * x))) *(u *(v * x)), \\
& =(u *(v * x)) *(u *(v * x)), \\
& =1 .
\end{aligned}
$$

Menurut Definisi 3.1(I2) $(a *(b * x)) * x \in S(u, v)$ dengan demikian (I1) dan (I2) terpenuhi artinya $S(u, v)$ adalah ideal.

Dengan menggunakan himpunan $S(u, v)$, maka dapat dideskripsikan karakteristik dari ideal.

Teorema 3.9. [3] Misalkan $S$ adalah semigrup implikatif komutatif dan misalkan I merupakan himpunan bagian tak kosong dari S. Maka I adalah ideal dari $S$ jika dan hanya jika $S(u, v) \subseteq I$ untuk semua $u, v \in I$.

Bukti. Misalkan $S$ adalah semigrup implikatif komutatif dan $I$ merupakan himpunan bagian tak kosong dari $S$. Akan ditunjukkan $I$ ideal dari $S$ jika dan hanya jika $S(u, v) \subseteq I$ untuk semua $u, v \in I$.

$(\Rightarrow)$ Asumsikan bahwa $I$ adalah ideal dari $S$ dan misalkan $u, v \in I$. Jika $z \in S(u, v)$ maka $u *(v * z)=1 \in I$ dan juga $z=1 * z=(u *(v * z)) * z \in I$ dari (I2). Jadi terbukti $S(u, v) \subseteq I$.

$(\Leftarrow)$ Sebaliknya, anggap $S(u, v) \subseteq I$ untuk semua $u, v \in I$. Perhatikan bahwa $1=u * 1=u *(v * 1) \in S(u, v)$. Misalkan $x, y, z \in S$ sedemikian rupa sehingga $(x *(y * z)) \in I$ dan $y \in I$. Karena $(x *(y * z)) *(y *(x * z))=(y *(x * z)) *(y *(x * z))=1$, maka diperoleh $x * z \in S(x *(y * z), y) \subseteq I$.

Teorema 3.10. [3] Misalkan $S$ merupakan semigrup implikatif komutatif. Jika I merupakan ideal dari $S$ maka

$$
I=\bigcup_{u, v \in I} S(u, v) .
$$

Bukti. Misalkan $S$ semigrup implikatif komutatif dan $I$ merupakan ideal dari $S$. Akan ditunjukkan bahwa $I=\bigcup_{u, v \in I} S(u, v)$. Misalkan $\forall x \in I$, maka $x \in S(x, 1)$ 
sehingga $I \subseteq \bigcup_{x \in I} S(x, 1) \subseteq \bigcup_{u, v \in I} S(u, v)$. Akan dibuktikan $\bigcup_{x \in I} S(x, 1) \subseteq$ $\bigcup_{u, v \in I} S(u, v)$. Ambil $y \in \bigcup_{x \in I} S(x, 1), \exists x \in I \ni x *(1 * y)=1$. Karena $1 \in I$, untuk setiap $u=x$ dan $v=1 \ni u *(v * y)=1$ berarti $y \in S(u, v)$ dan $y \in \bigcup_{u, v \in I} S(u, v)$. Sekarang misalkan $y \in \bigcup_{u, v \in I} S(u, v)$ kemudian terdapat $a, b \in I$ sehingga $y \in S(a, b)$. Ini mengikuti dari Teorema 3.9 bahwa $y \in I$. Karena $\bigcup_{u, v \in I} S(u, v) \subseteq I$ maka terbukti bahwa $I=\bigcup_{u, v \in I} S(u, v)$.

Akibat 3.11. [3] Jika I adalah ideal dari semigrup implikatif komutatif $S$ maka

$$
I=\bigcup_{w \in I} S(w, 1)
$$

\section{Contoh ideal pada semigrup implikatif}

Berikut akan diberikan contoh ideal yang dapat ditunjukkan dari definisi ideal dan dari suatu himpunan bagian $S$.

Contoh 4.1. Misalkan $S=\{1, a, b, c, d\}$ dan didefinisikan operasi terurut parsial di $S$ sebagai berikut :

$\langle i\rangle d \preceq b \preceq 1$.

$\langle i i\rangle d \preceq c \preceq a \preceq 1$.

Dari definisi relasi terurut parsial $\preceq$, dapat juga disajikan diagram Hasse berikut sebagaimana yang diperlihatkan pada Gambar 2.

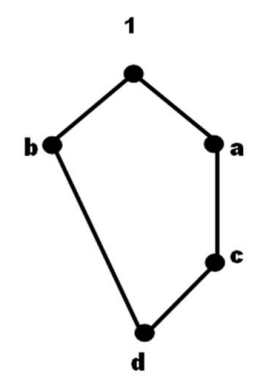

Gambar 2. Diagram Hasse untuk $\mathrm{S}=\{1, \mathrm{a}, \mathrm{b}, \mathrm{c}, \mathrm{d}\}$.

Tabel 3 dan 4 berikut adalah definisi dari operasi biner $\bullet$ dan $*$ di $S$.

Tabel 3. Definisi operasi • di $S$

\begin{tabular}{c|ccccc}
\hline$\bullet$ & 1 & $\mathrm{a}$ & $\mathrm{b}$ & $\mathrm{c}$ & $\mathrm{d}$ \\
\hline $\mathrm{l}$ & 1 & $\mathrm{a}$ & $\mathrm{b}$ & $\mathrm{c}$ & $\mathrm{d}$ \\
$\mathrm{a}$ & $\mathrm{a}$ & $\mathrm{a}$ & $\mathrm{d}$ & $\mathrm{c}$ & $\mathrm{d}$ \\
$\mathrm{b}$ & $\mathrm{b}$ & $\mathrm{d}$ & $\mathrm{b}$ & $\mathrm{d}$ & $\mathrm{d}$ \\
$\mathrm{c}$ & $\mathrm{c}$ & $\mathrm{c}$ & $\mathrm{d}$ & $\mathrm{c}$ & $\mathrm{d}$ \\
$\mathrm{d}$ & $\mathrm{d}$ & $\mathrm{d}$ & $\mathrm{d}$ & $\mathrm{d}$ & $\mathrm{d}$ \\
\hline
\end{tabular}


Tabel 4. Definisi operasi $*$ di $S$

\begin{tabular}{c|ccccc}
\hline$*$ & 1 & $\mathrm{a}$ & $\mathrm{b}$ & $\mathrm{c}$ & $\mathrm{d}$ \\
\hline $\mathrm{l}$ & 1 & $\mathrm{a}$ & $\mathrm{b}$ & $\mathrm{c}$ & $\mathrm{d}$ \\
$\mathrm{a}$ & 1 & 1 & $\mathrm{~b}$ & $\mathrm{c}$ & $\mathrm{d}$ \\
$\mathrm{b}$ & 1 & $\mathrm{a}$ & 1 & $\mathrm{c}$ & $\mathrm{c}$ \\
$\mathrm{c}$ & 1 & 1 & $\mathrm{~b}$ & 1 & $\mathrm{~b}$ \\
$\mathrm{~d}$ & 1 & 1 & 1 & 1 & 1 \\
\hline
\end{tabular}

Dengan menggunakan definisi ideal maupun definisi himpunan $S(u, v)$ dari $S=$ $\{1, a, b, c, d\}$ diperoleh idealnya yaitu apabila $I_{1}=\{1\}, I_{2}=\{1, a\}, I_{3}=\{1, b\}$, $I_{4}=\{1, a, b\}, I_{5}=\{1, a, c\}$ dan $S=\{1, a, b, c, d\}$. Selanjutnya, akan ditunjukkan $I=\bigcup_{u, v \in I} S(u, v)$ dengan memisalkan $S$ semigrup implikatif komutatif dan $I$ merupakan ideal dari $S$.

Untuk kasus $I=\{1, a\}$.

$\langle i\rangle S(1,1)=\{1\}$

$\langle i i\rangle S(1, a)=\{1, a\}$

$\langle$ iii $S(a, 1)=\{1, a\}$

$\langle i v\rangle S(a, a)=\{1, a\}$

Jadi benar $I=S(1,1) \cup S(1, a) \cup S(a, 1) \cup S(a, a)=\{1, a\}$.

\section{Ucapan Terima kasih}

Penulis mengucapkan terima kasih kepada Bapak Dr. Admi Nazra, Bapak Prof. Dr. I. Made Arnawa, Bapak Dr. Muhafzan, Bapak Dr. Mahdhivan Syafwan, Ibu Dr. Lyra Yulianti, dan Ibu Dr. Yanita yang telah memberikan masukan dan saran sehingga tulisan ini dapat diselesaikan dengan baik.

\section{Daftar Pustaka}

[1] Chan, M. W., dan Shum, K.P., 1993, Homomorphisms of implicative semigrups, Semigrup forum 46(1): 7 - 15

[2] Connell, 2002, Elements of Abstract and Linear Algebra, Math. Miami. Edu, Coral Gables, Florida

[3] Jun, Y.B., dan Kim, K. H., 2001, On ideals of implicative semigroups, International Journal of Mathematics and Mathematical Sciences 27(2): 77 - 82

[4] Nemitz, W.C., 1965, Implicative semi-lattices, Trans. Amer. Math. Soc. 117: $128-142$

[5] Piekart, B., dan Andrzej, W., 2011, On Filters and upper set in Cl-algebras, Journal Algebra and Discrete Mathematics 11 (1): 109 - 115 